grade of animal technician is recognized by many employing authorities, such as the Medical Research Council, which have undoubtedly learned that good animal technicians mean good animal material for research and investigation. Some universities recognize the grade, but others do not; the National Health Service does not, nor is the animal technician represented on the Whitley Council. Where recognition has occurred, it has been found to pay in terms of better animals, better work and (if costa are known) less extravagance through avoidable wastage. Why, then, are some employing bodies reluctant to follow the excellent lead given by others? No animal houses in Great Britain are so bad that they could not be worse; but many are not so good that they could not be better if unskilled labour were to be gradually replaced by qualified animal technicians.
Although we may regard our standards in Britain with some satisfaction (but with no complacency), too many laboratory animals still die of infection. Some of this wastage could be prevented by more skill employed in their care and management, by the application of existing knowledge of laboratory animal diseases, and by the investigation (mainly epidemiological) of diseases still imperfectly understood.

The symposium will be fully reported in Laboratory Animals Bureau Collected Papers, Vol. 4 (obtainable from the Bureau at the Medical Research Council Laboratories, Holly Hill, London, N.W.3). The Congress will be fully reported in the Journal of the Animal Technicians Association (obtainable from the honorary secretary of the Association, Mr. A. E. Mundy, 5 Ouse Bridge Drive, Carlton, Notts).

\section{W. LANe-Petter}

\title{
FOOD TECHNOLOGY AND NUTRITION
}

$\mathrm{T}$ HE 101st meeting of the Nutrition Society (the 46th meeting of the Scottish Group) was held in the Biochemistry Department of the University of Edinburgh on April 28, under the chairmanship of Prof. G. F. Marrian, when the subject of "The Impact of Food Technology on the Nutrition of Man and Animals" was considered. In opening the meeting, Prof. Marrian stressed the enormous importance of the topic under discussion, since so much food is processed. As one speaker pointed out, if it is accepted that food processing includes all treatment received by a foodstuff from its point of origin to the point in space and time when it is consumed, then barely 2 per cent of our food expressed in terms of calories receives no processing. Prof. Marrian also referred to the bigger and almost frightening problem of world food production, and suggested that the topics to be discussed that day warranted consideration over at least several days.

The first paper, on food processing and nutritional values for man, was by Dr. H. R. Barnell and Miss D. F. Hollingsworth, of the Ministry of Agriculture, Fisheries and Food. Miss Hollingsworth, who read the paper, pointed out that the application of heat to starch is essential for its digestion; that excessive heating of fat may cause production of acrolein; and that proteins are sensitive to the application of excessive heat and to the removal of heat. Starch, sugars and proteins in foods are not normally affected by atmospheric oxygen; but powerful oxidizing agents may have an effect. Fats may become rancid on storage, particularly in the presence of air. Rancidity may also be caused by the activity of micro-organisms. Development of oxidative rancidity is affected by temperature, light, moisture and by traces of various minerals (cobalt, copper, iron and manganese) and can be controlled by addition of antioxidants. Rancidity, besides reducing the value of fat, has adverse nutritional side-effects. Of the fat-soluble vitamins, vitamin $A$ is relatively stable to heat if oxygen is excluded. Light also accelerates oxidation. Vitamin $\mathrm{D}$ is moderately stable to heat, light and oxygen. Vitamin $\mathrm{E}$ is fairly stable to heat but is destroyed during development of oxidative rancidity in fats. Riboflavin and nicotinic acid are more stable to heat than vitamin $B_{1}$, which is the most labile of the $B$ complex. Riboflavin is unstable to heat and light. Vitamin $\mathrm{C}$ is unstable in presence of oxygen and is destroyed in sunlight.

It is possible that a combination of light, heat treatment and a radiation sterilization treatment will give eventually more attractive products than those produced by present methods. While on the whole it is true that the effects of processing on the nutrients in foods tend to give an impression of losses of nutrients whenever a food is given any form of treatment, it was emphasized by Miss Hollingsworth that the processing of foods is to a large extent a necessity to make them edible and palatable, transportable and storable. The final result is therefore greatly to increase the supply of nutrients to the world's populations.

Dr. J. M. Barnes, of the Medical Research Council's Toxicology Unit, followed next with a paper on the potential toxicity of chemicals used in food technology. He mentioned that many of the substances used as food additives possess no outstanding toxic property; others which may be used as adjuncts in processing or preservation may be toxic, but are present in the food only in very small quantities. The study of non-toxic substances resolves itself into the problem of trying to prove a negative.

Food manufacturers and allied commercial interests are so aware of the problem of toxicity that Dr. Barnes considered it unlikely that any material with demonstrable toxic properties will ever be included in food prepared in accordance with reputable trade practices. However, these may appear in food in trace quantities as the result of current practices such as compounds with well-marked toxic properties and active as insecticides, fungicides, germicides or endowed with other special properties. A safe dose is one which the body can dispose of without harm to its normal metabolism. Difficulties arise when no clearcut toxic response occurs with larger doses. There are some who suggest that in some unspecified way the prolonged consumption of such substances over long periods may injure health. It has been shown that, in the case of certain toxic substances, the disposal of small non-toxic doses may be quite different from that used when larger quantities are given. 
Dr. Barnes illustrated the biological complexities by reference to maleic hydrazide, a potato sprout depressant which produces inhibition of plant growth at concentrations of a few parts per million, and yet rats and other animals will grow and thrive on a diet containing as much as 1 per cent of it. When used properly, residues of $10-15$ p.p.m. may remain in the potatoes at the time they are consumed. It has been suggested by the work of Waggoner and Dimond that maleic hydrazide exerts its effects on plants by stimulating the enzymic hydrolysis of indole acetic acid, so depriving the plant of this auxin. But cytological changes include chromosome splitting. As many carcinogenic substances have a similar effect on mammalian cells, it has been suggested that maleic hydrazide should be tested for its carcinogenic effects before being used for human consumption. The uniformly negative result of tests on mammals suggests that maleic hydrazide on potatoes in 10-15 p.p.m. would not be harmful, though it does not amount to proof that it would be entirely safe. The steam volatility of another sprout depressant, tetrachloronitrobenzene, during cooking indicates that the physical and chemical properties of sub. stances added to food play as important a part as the biological properties in determining whether a health hazard will be associated with their use.

While there are comparatively simple acute tests which seem adequate for distinguishing powerful carcinogens, a definition of a 'weak carcinogen' has not been provided. Surface-active agents may have interesting biological effects; but whether or not these effects will be shown if the emulsifiers are added to bread has not yet been determined.

Not only may the chemicals added to food become altered, but so too may the food itself and the products of such reactions might be toxic. The classical example is the agone process of improving flour. Agenized flour is toxic to dogs, cats, rabbits and ferrets, but rats and monkeys are relatively insensitive. Dr. Barnes quoted experiments in the United States on nineteen humans, including five epileptics, who were given flour treated with 20-30 times the usual quantity of agene but without showing any change in behaviour, general physiology or electro-encephalogram. The monkey requires at least a hundred times the dose of the active toxic agent, methionine sulphoximine, needed to induce fits in the dog. A man eating 2,000 Cal. per day as agene-treated flour ingests a dose of $1 \mathrm{mgm} . / \mathrm{kgm}$. methionine sulphoximine; the sensitive dog requires a dose of 2-4 mgm. $/ \mathrm{kgm}$. to produce fits and kill the animal. The nature of the toxic action of methionine sulphoximine has not been defined: species differences may be due to speed and ability to dispose of the toxic substance.

Where no positive effects can be observed on animals with a given substance, then a hypothetical risk may be incurred if such a chemical is added to food. In Dr. Barnes's view, this should in some way be balanced by the simultaneous conferment of some benefit to those who incur this risk.

Mr. N. W. Pirie, of the Rothamsted Experimental Station, in his paper on unexploited technological possibilities, pointed out that the three outstanding possibilities for increased food are : the synthesis of food, the more economical use of crops of the type we already grow, and the exploitation of new primary sources of food. In his opinion we would continue to rely mainly on photosynthesis rather than on syn. thesis of the bulk foods. Few people get less than half their energy from vegetable sources, and most of the world's population gets nearly all its energy in this way. One solution of the food problem would therefore be to increase the amount grown.

Diets eaten in many parts of the world are inadequate, having many faults; protein deficiency being a common one. Some legume seeds contain adequate amounts of protein; but many tubers such as cassava contain very little. Many leaves, which can now be stored by refrigeration, contain as much nitrogen as the legume seeds. Investigation of systems of husbandry that would ensure large yields of protein-rich and fibre-poor leaves is a technological possibility that deserves fuller exploitation. Even normally despised grasses would be useful if grown regularly with 25-30 per cent of protein.

The protein in the leaf is already there and valuable, needing only separation from dilute carbohydrate. Since the time of Rouelle (1773) it has been extracted from leaves and coagulated. The pulper described by Mr. Pirie is the end-product of much experiment, and is reasonably satisfactory in separating juice from fibre. The protein can be precipitated from the juice by letting it age, by heating to $75^{\circ} \mathrm{C}$., by adjusting $p \mathrm{H}$ to about 4 or by shaking it with a variety of water-immiscible liquids. Different preparations vary somewhat in digestibility, and the reasons for this are being investigated. Mr. Pirie thinks it wise to postpone careful feeding-trials until this phenomenon is more fully understood; but he stresses the need for a much more adequate scale of research in this important field. He considers it illusory to believe that algae, such as Chlorella, are peculiarly efficient at trapping light and giving a greater return per acre-year than other crops.

'The sea is an under-exploited environment, and both the harvesting of marine microflora and the use of the material harvested are ripe for technological investigation. Mr. Pirie believes that, if Britain cannot continue to buy its food from the rest of the world, it must come to live on its own acres and then it must change its style of eating.

In his account of some technological developments of importance in animal nutrition, Dr. J. Duckworth first pointed out that most of the common energy sources are often too low in protein for productive purposes and must be supplemented to secure appropriate ratios of metabolizable energy to digestible protein. All protein-rich supplements are expensive, relative to the basic energy sources, and thus minimum feeding costs are realized only when supplements are added at the level that justifies the animal's needs. In practice, a margin of safety must be added, and the greater the uncertainty about the dietary protein the greater this margin must be. Sources of uncertainty are: variation in protein content among different batches of individual feeding-stuffs, variation in amino-acid composition within the total protein content, natural variation in protein digestibility, and variable effects of processing on protein quality, defined in terms of digestibility and of metabolic availability of certain important amino-acids of the digested protein. An independent source of uncertainty is variation in the metabolizable energy of feeding-stuffs disturbing the nutritive ratio.

Important features of research and technical development are studies on processing to obtain by-products of uniformly high protein value, of the inheritance of desirable amino-acid levels in feed proteins, of the synthetic production of amino-acids 
and of applying nitrogenous fertilizers to raise the protein content of crops of high-energy content.

In Britain there is the problem of making efficient rations for the livestock with feeding-stuffs of diverse and fluctuating origin and kind. The nation is dependent on the technological capacity of manufacturers abroad; for example, half the national supply of protein concentrates was imported in 1953 and 1954. In 1955 there was a large increase in supplies, mainly of imported oilseed meals. So far, continued Dr. Duckworth, little research on the nutritive value and still less on local processing methods has been published from most sources of these feeding-stuffs. Processing has generally a profound effect on the nutritive value of protein concentrates and, if inadequately controlled, yields highly variable products. Only on fish, herring, soyabean and cotton-seed meals has extensive research been done, and then almost entirely from the point of view of suiting the products to non-ruminant needs. A recent trend has been to process oil-seed meals for high solubility of protein. Such materials are contra-indicated for ruminants under preferred British feeding systems. Attention is now being given to developing rapid laboratory tests of protein quality. If success is attained, an appropriate amendment of the Fertilizer and Feeding Stuffs Act would give protection against low-value protein concentrates of domestic or imported origin, and thus lead to more efficient compounding of rations.

Many members and visitors took part in the discussion which followed.

\section{SCIENCE HOUSE, PAKISTAN}

$\mathrm{T}$ $\mathrm{HE}$ visitor to Pakistan cannot fail to be impressed by the rapid scientific development which is taking place there. The science departments in the older universities are expanding; new universities have been created in Sind, Karachi, Peshawar and Rajshahi; the Central and three Regional Laboratories of the Pakistan Council of Scientific and Industrial Research have been established, and important research institutions, such as the Cotton Research Institute, the Jute Research Laboratory, the Pakistan. Standards Laboratory and others, have come into being during the past three years. The new buildings, many of which have been completed, are very impressive. The sites are spacious and convenient, and the buildings, of pleasing design, have been planned with imagination and foresight. There is ample accommodation for many years to come, and expansion will not be hampered by considerations of space. These institutions have been provided by the State, and are a reflexion of the importance attached by the Government to the part which science must play in the development of the country.

The Pakistan Association for the Advancement of Science was founded in 1947, and has been very active, having started the publication of Pakistan's first scientific journals-the Pakistan Journal of Science and the Pakistan Journal of Scientific Research-and organized the annual All-Pakistan Science Conferences.

A new development of great importance has just been launched. The foundation stone of the Ismail Aiwan-i-Science (Sciénce House), Lahore, was laid on January 27, 1956, jointly by Mr. Nasser Ahmad
Shaikh, and the representatives of science associations from Australia, China, India, Pakistan, the U.S.S.R., the United Kingdom and the United States.

Science House will be the integrating centre for science in Pakistan. It will contain a large science library and a bibliographic, translation and documentation centre equipped for microfilming and duplication. There will be an auditorium to seat a thousand persons. There will be accommodation for a Human Relations Research Centre, which will be concerned chiefly with social science research. Science House will also contain office accommodation for the various scientific societies, together with seminar and committee rooms, and a press and publications section for the various scientific societies and organizations. There will be residential accommodation for visiting scientists, club rooms and a cafeteria.

The building is situated in the new modern residential centre of Lahore, adjacent to the new Regional Laboratories of the Council of Scientific and Industrial Research, and close to a number of important educational institutions and the proposed new site for the University of the Panjab.

This magnificent project was conceived by Dr. Bashir Ahmad and his colleagues, and has been made possible through the generosity of Mr. Nasser Ahmad Shaikh, a leading industrialist in Pakistan, who has provided the funds for building Science House.

The new building will be completed early in 1957, and the next annual meeting of the Pakistan Association for the Advancement of Science will be held in it.

George Aruen

\section{OBITUARIES}

\section{Dr. Walter Sydney Adams, For.Mem.R.S.}

Walter Sydney Adams, the son of a missionary, was born in Antioch in northern Syria on December 20, 1876. He was educated at Dartmouth College and the Universities of Chicago and Munich, and was appointed an assistant at the Yerkes Observatory under Hale in 1901. In 1904 he was one of the small staff which went with Hale to Mount Wilson to start the new Observatory in California. As assistant astronomer, as assistant director, as acting director during Hale's illness, and from 1923 onwards as director, he devoted his life to the Observatory until his retirement in 1946. As a research associate of the Carnegie Institution of Washington and of the California Institute of Technology, he continued working on astrophysical problems, his last paper on the shell star $\alpha$ Orionis appearing in the March issue of the Astrophysical Journal this year. $\mathrm{He}$ died on May 11, 1956.

Adams's earliest publications were on line-of-sight velocities of stars, on spectroscopic binary orbits, on stars of variable velocity and on details of spectro. 